\title{
A test of reproductive skew models in a field population of a multiple-queen ant
}

\author{
R. L. Hammond • M. W. Bruford • A. F. G. Bourke
}

Received: 7 April 2006 /Revised: 16 June 2006 / Accepted: 6 July 2006 / Published online: 16 September 2006

(C) Springer-Verlag 2006

\begin{abstract}
Determining the evolutionary basis of variation in reproductive skew (degree of sharing of reproduction among coexisting individuals) is an important task both because skew varies widely across social taxa and because testing models of skew evolution permits tests of kin selection theory. Using parentage analyses based on microsatellite markers, we measured skew among female eggs $(n=32.3$ eggs per colony, range $=20-68)$ in 17 polygynous colonies from a UK field population of the ant Leptothorax acervorum. We used skew among eggs as our principal measure of skew because of the high degree of queen turnover in the study population. Queens within colonies did not make significantly unequal contributions to queen
\end{abstract}

Communicated by K. Ross

R. L. Hammond · A. F. G. Bourke

Institute of Zoology, Zoological Society of London,

Regent's Park,

London NW1 4RY, UK

M. W. Bruford

School of Biosciences, Cardiff University,

Cathays Park,

Cardiff CF10 3TL, UK

R. L. Hammond $(\bowtie)$

Department of Ecology and Evolution, Biophore,

University of Lausanne,

CH 1015 Lausanne, Switzerland

e-mail: Rob.Hammond@unil.ch

Present address:

A. F. G. Bourke

School of Biological Sciences,

University of East Anglia,

Norwich NR4 7TJ, UK and worker adult or pupal offspring, indicating that skew among female eggs reflected skew among daughter queens. On average, both skew among female eggs (measured by the $B$ index) and queen-queen relatedness proved to be low (means $\pm \mathrm{SE}=0.06 \pm 0.02$ and $0.28 \pm 0.08$, respectively). However, contrary to current skew models, there was no significant association of skew with either relatedness or worker number (used as a measure of productivity). In $L$. acervorum, predictions of the concession model of skew may hold between but not within populations because queens are unable to assess their relatedness to other queens within colonies. Additional phenomena that may help maintain low skew in the study population include indiscriminate infanticide in the form of egg cannibalism and split sex ratios that penalize reproductive monopoly by single queens within polygynous colonies.

Keywords Kin selection · Polygyny - Reproductive skew . Social evolution $\cdot$ Social insect

\section{Introduction}

The extent to which coexisting breeding individuals share reproduction varies greatly across animal societies. Societies with high reproductive skew are those in which one or a few individuals monopolize reproduction; societies with low reproductive skew occur when breeders share reproduction more evenly. The extension by Reeve (1991) and Reeve and Ratnieks (1993) of the original skew models of Vehrencamp $(1979,1983)$ and Emlen $(1982 a, b)$ has led to a wealth of new models aimed at explaining skew variation within and between species, along with a growing number of empirical tests of these models. The importance of these studies arises because skew models offer a potential explanation for the 
Table 1 Assumptions of models of reproductive skew and the models' predicted correlations

\begin{tabular}{|c|c|c|c|c|c|c|}
\hline & \multicolumn{3}{|l|}{ Transactional models } & \multirow{2}{*}{$\begin{array}{l}\text { Compromise } \\
\text { models } \\
\text { Tug-of-war } \\
\text { models }\end{array}$} & \multirow{2}{*}{$\begin{array}{l}\text { Synthetic } \\
\text { model }\end{array}$} & \multirow{2}{*}{$\begin{array}{l}\text { Results } \\
\text { of present } \\
\text { study }\end{array}$} \\
\hline & $\begin{array}{l}\text { Concession } \\
\text { models }\end{array}$ & $\begin{array}{l}\text { Resource } \\
\text { inheritance } \\
\text { models }\end{array}$ & $\begin{array}{l}\text { Restraint } \\
\text { models }\end{array}$ & & & \\
\hline \multirow[t]{3}{*}{$\begin{array}{l}\text { Main } \\
\text { assumptions: }\end{array}$} & $\begin{array}{l}\text { 1. Dominant } \\
\text { controls group } \\
\text { membership }\end{array}$ & $\begin{array}{l}\text { 1. Dominant } \\
\text { controls group } \\
\text { membership }\end{array}$ & $\begin{array}{l}\text { 1. Dominant } \\
\text { controls group } \\
\text { membership }\end{array}$ & $\begin{array}{l}\text { 1. Limited control } \\
\text { by both parties }\end{array}$ & $\begin{array}{l}\text { 1. Synthesized } \\
\text { assumptions of } \\
\text { transactional and } \\
\text { compromise } \\
\text { models }\end{array}$ & \\
\hline & \multirow[t]{2}{*}{$\begin{array}{l}\text { 2. Dominant } \\
\text { controls skew }\end{array}$} & $\begin{array}{l}\text { 2. Dominant } \\
\text { controls skew }\end{array}$ & \multirow[t]{2}{*}{$\begin{array}{l}\text { 2. Subordinate } \\
\text { controls skew }\end{array}$} & \multirow[t]{2}{*}{$\begin{array}{l}\text { 2. Gaining share } \\
\text { of reproduction } \\
\text { is costly }\end{array}$} & & \\
\hline & & $\begin{array}{l}\text { 3. Subordinate } \\
\text { inherits } \\
\text { dominant's } \\
\text { resource }\end{array}$ & & & & \\
\hline \multicolumn{7}{|l|}{ Predictions: } \\
\hline $\begin{array}{l}\text { 1. Skew vs } \\
\text { relatedness }\end{array}$ & $\begin{array}{l}\text { Positive }^{\mathrm{a}, \mathrm{b}, \mathrm{c}} \\
\text { or Negative }^{\mathrm{b}, \mathrm{c}}\end{array}$ & $\begin{array}{l}\text { Positive } \\
\text { or Negative }\end{array}$ & Negative & $\begin{array}{l}\text { Negative or no } \\
\text { correlation }\end{array}$ & $\begin{array}{l}\text { Positive } \\
\text { or Negative }\end{array}$ & No correlation \\
\hline $\begin{array}{l}\text { 2. Skew vs } \\
\text { degree of } \\
\text { ecological } \\
\text { constraint }\end{array}$ & Positive $^{\mathrm{a}, \mathrm{b}}$ & - & Negative & No correlation & $\begin{array}{l}\text { Positive } \\
\text { or Negative }\end{array}$ & Not studied \\
\hline $\begin{array}{l}\text { 3. Skew vs } \\
\text { per capita } \\
\text { productivity }\end{array}$ & Positive $^{\mathrm{a}}$ & - & Negative & No correlation & $\begin{array}{l}\text { Positive } \\
\text { or Negative }\end{array}$ & No correlation \\
\hline $\begin{array}{l}\text { 4. Relatedness vs } \\
\text { group } \\
\text { productivity }\end{array}$ & No correlation $^{\mathrm{a}}$ & - & No correlation & Positive & - & No correlation \\
\hline $\begin{array}{l}\text { Selected } \\
\text { references }\end{array}$ & $\begin{array}{l}\text { Reeve and Ratnieks } \\
(1993)^{\mathrm{a}} \text {; Cant and } \\
\text { Johnstone }(1999)^{\mathrm{b}} \text {; } \\
\text { Johnstone et al. } \\
(1999)^{\mathrm{c}}\end{array}$ & $\begin{array}{l}\text { Kokko and } \\
\text { Johnstone (1999); } \\
\text { Ragsdale (1999) }\end{array}$ & $\begin{array}{l}\text { Johnstone and } \\
\text { Cant (1999b) }\end{array}$ & $\begin{array}{l}\text { Reeve et al. } \\
\text { (1998) }\end{array}$ & Johnstone (2000) & \\
\hline
\end{tabular}

Superscripts indicate predictions varying depending on detailed assumptions. -, no prediction made or not considered in this study. See also Cant (1998, 2006), Johnstone and Cant (1999a), Cant and Johnstone (2000), Reeve (2000), Reeve and Emlen (2000), Kokko (2003) and Zink and Reeve (2005).

wide variation in skew observed across animal societies. In principle, skew models also provide a means of testing kin selection theory (Hamilton 1964), on which they are based.

The many skew models now present in the literature differ in both their assumptions and in the predictions they make regarding the expected genetic, ecological, demographic and social correlates of skew (Table 1). Empirical studies of skew in both invertebrates and vertebrates (reviews in: Keller and Reeve 1994; Emlen 1997; Reeve and Keller 2001) have tended to lag behind the development of new models. This is because the assumptions of skew models are either not met or are difficult to verify, skew and its predicted correlates are not always simple to measure and different skew models make overlapping predictions (Clutton-Brock 1998; Magrath and Heinsohn 2000; Table 1). The social Hymenoptera have been recognized as a particularly apt group for empirical tests of skew models because skew varies widely even among closely related species, a relatively large number of social groups can be sampled and insects lend themselves to experimental manipulation. However, conclusions from empirical studies have been mixed. Some studies have found support for concession models of reproductive skew (e.g., social wasps: Reeve et al. 2000; Sumner et al. 2002; see also Nonacs et al. 2004), some for tug-of-war models (e.g., social wasps: Seppä et al. 2002; social bees: Langer et al. 2004, 2006) and others have found no clear support for any current model (e.g., social wasps: Field et al. 1998; 
Fanelli et al. 2005; Liebert and Starks 2006; Nonacs et al. 2006; ants: Fournier and Keller 2001; Rüppell et al. 2002; Hannonen and Sundström 2003a; Fournier et al. 2004). One reason for these mixed results could be that not all tested species share the same model assumptions (Table 1). Whatever its causes, this situation creates a clear need for additional empirical studies so that the balance of evidence can be properly assessed.

The leptothoracine ants represent a group in which an understanding of the factors underlying variation in skew would be especially valuable because some species exhibit multiple-queen societies in which a single queen monopolizes reproduction (i.e., functional monogyny), whereas in other multiple-queen (polygynous) species, reproduction is more evenly distributed among queens (Buschinger 1974; Bourke and Heinze 1994). Leptothoracines most closely match the assumptions of concession models of skew (Bourke and Heinze 1994; Rüppell et al. 2002). For example, the maintenance of functional monogyny by aggressive dominance (Heinze and Lipski 1990; Heinze and Smith 1990) suggests that complete control of skew by dominants is possible (Table 1). In addition, the presence of subordinates increases the productivity of dominant queens, although the mechanism underlying this effect is unclear (Heinze and Oberstadt 2003). Consistent with concession models, broad-scale comparisons in leptothoracines (i.e., at the between-population and between-species level) suggest positive correlations of skew with relatedness (Heinze 1995; Heinze et al. 1995b; Bourke et al. 1997) and inferred levels of ecological constraint (Bourke and Heinze 1994; Felke and Buschinger 1999). In contrast, a comprehensive study of L. rugatulus on skew variation among colonies (which either had been kept in the laboratory for 11 months or were artificially composed) found no support for concession models (Rüppell et al. 2002). However, to date, no study has examined skew as a function of predicted correlates among colonies within a field population of leptothoracines.

We investigated the covariation of skew, relatedness and productivity within a field population of the facultatively polygynous Leptothorax acervorum. We did not include ecological constraint (Table 1) in our study. This is because it is unlikely that $L$. acervorum queens are able to assess within-population levels of ecological constraint since readopted queens in polygynous colonies almost certainly mate near the nest and, if they disperse following the initiation of reproduction, do so on foot (Douwes et al. 1987; Bourke and Heinze 1994; Felke and Buschinger 1999; Hammond et al. 2001). Therefore, queens are most likely to have evolved to adjust their reproductive output in response to the average, population-level degree of ecological constraint, which is invariant for queens within a population.

\section{Methods}

Field collection and colony sampling

We studied L. acervorum in Thetford Forest, Norfolk, UK. In this population, approximately $20-50 \%$ of colonies are polygynous with a mean of two to five related queens per colony, 95\% of which are singly mated (Chan and Bourke 1994; Heinze et al. 1995a; Bourke et al. 1997; Hammond et al. 2001-2003). Sex ratios are split, with monogynous colonies producing mainly females and polygynous colonies producing mainly males (Chan and Bourke 1994; Chan et al. 1999; Hammond et al. 2002). Collections of colonies were made in 1999 ('SD99' colonies) and 2000 ('SD00' colonies). The SD99 colonies ( $n=46$, collected on June 3 and June 10) are the same as those whose collection is described by Hammond et al. (2001) and for which we have previously presented genetic analyses of traits other than reproductive skew (Hammond et al. 2001-2003). The SD00 colonies ( $n=100$, collected between July 27 and August 24) came from a site approximately $1 \mathrm{~km}$ away. We have not previously presented data on the SD00 colonies. All SD99 colonies and 39 SD00 colonies were located by random searching (the remaining 61 SD00 colonies were located by searching in the area defined by a circle of 2-m radius centred on each of the focal 39 colonies). Only data from the 39 SD00 colonies located by random searching are presented in the current paper. After discovery, all colonies in both samples were collected using methods described in Chan and Bourke (1994). All adults and brood were extracted from their twigs within a few days of collection and frozen for later genetic analysis. Colony composition therefore reflected that found in the field at the time of collection.

We investigated reproductive skew in a subset of 17 polygynous colonies (9 SD99 colonies and 8 SD00 colonies). Polygynous colonies were defined as those containing more than one dealate, mated queen (henceforth, 'queens'; dealate queens are those that have shed their wings). We determined the insemination status of queens by noting the presence of a full or empty sperm receptacle upon ovarian dissection (Bourke 1991; Hammond et al. 2001). We selected 9 polygynous colonies with 2-8 queens per colony (mean $\pm \mathrm{SD}=3.6 \pm 1.8$ queens) from the SD99 sample (i.e., the 9 polygynous colonies in Table 1 of Hammond et al. 2001). In the SD00 sample, 11 of the 39 focal colonies proved to be polygynous, but we omitted 3 of these 11 colonies from our skew analysis. In two of the omitted colonies, parentage analyses could not be conducted because both colonies contained high numbers (16 and 17) of closely related queens, which therefore shared many alleles. Omitting these colonies is unlikely to have biased our results since, in the remaining colonies, relatedness varied across the whole spectrum of likely values $(-0.01-0.89)$, indicating 
that the exclusion of these two colonies did not truncate variability in relatedness. The third SD00 colony was omitted because it contained no eggs. In the eight SD00 colonies in which we measured skew, there were $2-7$ queens per colony (mean $\pm \mathrm{SD}=3.4 \pm 2.0$ queens).

\section{Molecular methods}

We genotyped individuals using the microsatellite loci LXAGT1, LXAGA1, LXAGA2 (Bourke et al. 1997), MYRT3 (Evans 1993), LXGT223 (Hamaguchi et al. 1993) and L18 (Foitzik et al. 1997), using methods described by Hammond et al. (2001). In the Thetford Forest population, these loci have a mean expected heterozygosity of 0.88 and a mean of 23 alleles per locus (Hammond et al. 2001). In the SD99 colonies, a total of 32 queens and the contents of 29 corresponding sperm receptacles (3 were lost during dissection) were genotyped at a mean of 6.0 loci (range $=4-6$ ), as described in Hammond et al. (2001). In the SD00 colonies, a total of 27 queens and the contents of 27 corresponding sperm receptacles were genotyped at a mean of 3.6 loci $($ range $=2-4)$. Genotyping of the contents of sperm receptacles had a high failure rate $38 \%$ in SD99 samples and $30 \%$ in SD00 samples). In SD99 colonies, as described in Hammond et al. (2001), we also typed a per colony mean of 12.8 adult workers ('old workers', range $=0-15$ ), 13.9 callow workers or worker pupae ('new workers', range $=0-19), 10.3$ adult males (range $=0-19$ ) and 6.7 alate (winged) queens or queen pupae ('new queens', range $=0-21$ ) at a mean of 6.0 loci. Finally, across both sets of colonies, we genotyped a mean of 42.6 eggs per colony at a mean of 2.0 loci $($ range $=1-4$ ). These consisted of a mean (range) of 54.9 (36-89) eggs from the SD99 colonies (the samples described in Hammond et al. (2003) plus a few additional SD99 eggs) and a mean (range) of 28.8 (20-38) eggs from the SD00 colonies. Eggs were genotyped at loci found to be diagnostic for parentage analyses on the basis of the genotypes of queens and the queens' mates (the genotypes of the queens' mates being deduced from those of the contents of the sperm receptacles or those of female progeny). Within colonies, we attributed female (diploid) eggs to one of the queens using exclusion criteria. The high degree of genetic variation per locus, together with the absence of relatedness between $L$. acervorum queens and their mates and between mates of coexisting queens (Hammond et al. 2001), meant that almost all eggs could be assigned to individual queens (see 'Parentage analysis' under 'Results').

\section{Relatedness}

We estimated regression relatedness among coexisting queens in the SD00 colonies and, for the SD99 colonies, used relatedness values calculated previously (Hammond et al. 2001-2003). In the SD00 colonies, we calculated Queller and Goodnight's (1989) regression relatedness from genotype data with the program RELATEDNESS 5.07 (Goodnight Software: http://www.gsoft.smu.edu/Gsoft.html).

\section{Colony productivity}

In both the SD99 and SD00 colonies, we used the number of adult workers as a surrogate measure of colony productivity. This was justified because, based on previous data from polygynous colonies in the study population in Chan et al. (1999), we found colony sexual production (measured as biomass of either new queens, or males or new queens and males combined) to be highly correlated with number of adult workers (all Pearson's $r>0.47$, all $n=30$, all $P<0.009$ ).

\section{Queen turnover}

Previous work has shown that polygynous colonies of $L$. acervorum in the study population have a high rate of queen turnover, with large proportions of old workers, new queens and males being unattributable to resident queens (Bourke et al. 1997; Hammond et al. 2001). In the present study, we estimated the degree of queen turnover in SD99 colonies only since no adults or pupae were genotyped in SD00 colonies. We estimated the genetically effective turnover of queens $(\tau)$ across pairs of female age cohorts using Eq. 4 in Pedersen and Boomsma (1999). This defines 100\% turnover as occurring when all queens contribute to one cohort only and $0 \%$ turnover as occurring when all queens contribute to both cohorts. The variables used in the estimation of $\tau$ are the relatednesses within and between the two age cohorts being compared. We measured relatednesses within and between female eggs, new workers, old workers and new queens. Relatednesses were averaged across colonies for the estimation of population-level turnover. Since $L$. acervorum workers overwinter once as larvae, whereas queens usually overwinter twice (Buschinger 1973), we assumed that, relative to eggs, new workers were $0-1$ years older, old workers were $>1$ year older and new queens were 2 years older. These relative ages are approximate because some workers may eclose in the year that they were laid as eggs, the longevity of adult workers is unknown, and some queens may overwinter as larvae only once. Nonetheless, comparing relatedness within and between female eggs and these cohorts allowed us to estimate queen turnover across an ever-increasing age interval.

Reproductive skew

The likely occurrence of high queen turnover meant that reproductive skew could not easily be calculated 
from the genotypes of adult or pupal progeny. We therefore measured skew in samples of female eggs (SD99 colonies: mean=44.8 female eggs per colony, range $=28-77$; SD00 colonies: mean=25.0 female eggs per colony, range $=20-33$ ). This assumed that individual queens within colonies did not differ in the queen-toworker ratio among their progeny (we consider other assumptions in 'Discussion'). We were able to test this assumption by comparing the proportion of either caste attributable to each queen in four SD99 colonies with sufficient numbers of new workers and new queens. In one of these colonies (SD99.54), we included as a maternal queen an individual that was not present at collection but whose existence could be inferred from the genotypes of her daughters, i.e., a 'lost' queen (Hammond et al. 2003). In each colony, a minority of new workers and new queens could be not be assigned to either resident or lost queens. We therefore grouped these progeny into a 'queen unknown' parentage class.

We did not investigate reproductive skew among male eggs for two reasons. First, the sample sizes for male eggs in each colony were small because in L. acervorum, only a small minority of eggs laid by queens $(16 \%)$ are male and workers lay very few male eggs (Hammond et al. 2002, 2003). Second, parentage assignment of males, being haploid, was much more difficult than for females because queens often shared a high proportion of alleles (frequently, it was the paternal alleles in females that allowed parentage assignment). However, in five SD99 colonies, the sample size of adult, queen-produced males was large enough and parentage assignment was possible. In these colonies, we investigated whether reproductive skew differed between sexes of progeny by comparing the proportion of adult males and new workers attributable to each queen within the colonies. We did not compare adult males and new queens because such a comparison would have been confounded by year since usually queens take 2 years to develop, whereas workers and males take only 1 year (Buschinger 1973). As in our comparison of skew between castes, progeny that could not be assigned to either resident or lost queens were grouped into a 'queen unknown' parentage class.

We used Nonacs's $B$ index (Nonacs 2000, 2003) to quantify skew in female eggs. Using the program SKEW CALCULATOR 2003 (Nonacs 2003), we calculated $B$, the $95 \%$ confidence limits of $B$ (using 10,000 randomizations) and, given the queen number in each colony, the maximum (where only one queen reproduces in each colony) and minimum (where all queens reproduce equally) possible values of $B$. To control for the maximum and minimum values of $B$ varying across colonies (P. Nonacs, personal communication), we also calculated an adjusted $B$ index $\left(B_{\text {adj }}\right)$. We calculated this as the absolute difference between the observed and minimum $B$ values divided by the absolute difference between the maximum and minimum $B$ values.

\section{Statistical methods}

Queen-queen relatedness ('relatedness'), colony size ('worker number', i.e., number of old workers), reproductive skew (as measured by $B$ or $B_{\text {adj }}$ ) and the number of queens per colony ('queen number') were all normally distributed (Kolmogorov-Smirnov tests, all $P>0.05$ ). There was no significance difference in any variable across sampling years (SD99 vs SD00: all $t_{15}<1.07$, all $P>0.30$ ), so data were pooled across years for further analyses. We tested relationships predicted by the skew models (Table 1) in two general linear models (GLM). First, in 'skew GLM', we tested whether skew ( $B$ or $B_{\text {adj }}$ ) varied with relatedness, queen number and worker number (as a measure of productivity). We also tested whether skew varied with productivity per queen by testing in these analyses for an interaction between queen and worker number. Second, in 'productivity GLM', we tested whether worker number varied with relatedness. In addition, in 'queen number GLM', we tested whether relatedness varied with queen number. All GLM analyses were carried out with SPSS (version 12.0.0). To compare skew between castes (new queens vs new workers) and sexes (males vs new workers), we used exact tests calculated by the program $\mathrm{R} \times \mathrm{C}$ [Miller MP (1997) $\mathrm{R} \times \mathrm{C}$ : a program for the analysis of contingency tables, 1.0 edn. Department of Biological Sciences, Northern Arizona University, Flagstaff]. Where multiple tests were performed on the same data, we applied sequential Bonferroni correction (Rice 1989).

\section{Results}

Relatedness and queen turnover

Average queen-queen relatedness (mean \pm SE) was $0.28 \pm 0.08$ ( $n=59$ queens from 17 colonies). The genetical effective turnover of queens $(\tau$ ) was $50.3 \%$ (comparing eggs vs new workers, $n=8$ colonies), $43 \%$ (comparing eggs vs old workers, $n=8$ colonies) and $67.2 \%$ (comparing eggs vs new queens, $n=5$ colonies). Therefore, queen turnover was substantial and, as expected, showed evidence of rising as the age interval between cohorts increased (with the reversal of values between eggs vs new workers and eggs vs old workers, relative to those expected, presumably stemming from high overlap between the ages of new and old workers and from sampling error in the underlying relatedness estimates). These results, coupled with the complementary finding that a mean of $27 \%$ of new 
workers, new queens and old workers were not assignable to resident queens (see below) and with previous findings from the same population (Bourke et al. 1997), provided support for measuring skew among eggs in this study.

Parentage analysis

We could successfully attribute $91 \%$ (550 out of a total $n=603$ ) of all female eggs to individual resident queens. The remaining $9 \%$ were either not attributable to any resident collected queen $(8 \%)$ or were equally likely to be the offspring of two or more resident queens (1\%). Almost half of the eggs that were unattributable to resident queens were found in two colonies (SD99.74 and SD99.96); omitting these raised the proportion of successfully assigned eggs to $95 \%$. In our analysis of skew (see below), we ignored the small fraction of unattributed eggs and analyzed skew in the large majority of eggs whose maternity we could deduce. Furthermore, we included all colonies since the omission of the two colonies with the highest proportions of unattributable eggs did not alter the results. Compared to female eggs, a lower proportion of adult males $(82 \%)$, new queens $(64 \%)$, new workers $(69 \%)$ and old workers $(85 \%)$ could be attributed to resident queens.

Variation in skew as measured across castes and sexes

There were no significant differences between the proportion of new queens and new workers attributable to each resident queen in all four SD99 colonies where comparisons were possible (Table 2), supporting our assumption that skew in female eggs provides an accurate estimate of reproductive skew in new queens. However, there were significant differences between the proportion of males and new workers attributable to each resident queen in all five SD99 colonies where comparisons were possible (Table 3).
Queens coexisting within the same colony therefore differed in their relative success at producing male and female offspring, with some concentrating on male production and others on female production.

Average reproductive skew

Reproduction was relatively equitably distributed among queens, with only 4 of 59 resident queens (6.8\%) failing to contribute any female eggs (Fig. 1). The highest proportion of eggs contributed by a single queen was $69.2 \%$ in a colony with 3 queens (colony SD00.129; Fig. 1). Average skew across colonies was low, with the overall mean $( \pm \mathrm{SE})$ of $B$ equalling $0.06 \pm 0.02$ and of $B_{\text {adj }}$ equalling $0.12 \pm 0.03$ (Fig. 2). The mean level of $B$ (randomization test, $P<0.0001$ ) and skew in 5 of 17 colonies (randomization test, $P<0.004$, corresponding to an overall alpha of 0.05 ) was significantly greater than that expected by chance (Fig. 2). However, even in the 5 colonies with significant skew, skew estimates were nearer their minimum than their maximum level (Fig. 2).

Relationship of reproductive skew with relatedness, worker number and queen number

We found no significant relationship of skew with relatedness, queen number or worker number (skew GLM, $B: F_{4,12}=0.99, P=0.45 ; B_{\text {adj }}: F_{4,12}=0.73, P=0.59$; Fig. 3). There was also no significant interaction between queen number and worker number $\left(B: F_{1,12}=2.91, P=0.11 ; B_{\text {adj }}\right.$ : $\left.F_{1,12}=2.52, P=0.14\right)$. Bivariate linear regressions showed that our analyses had relatively high power because the standard deviations of the relevant regression coefficients were small ( $B$ vs relatedness: $b \pm \mathrm{SD}=-0.03 \pm 0.06$, $F_{1,15}=0.18, \quad r^{2}=0 \%, P=0.67 ; B$ vs queen number: $b \pm \mathrm{SD}=0.01 \pm 0.01, F_{1,15}=0.96, r^{2}=0 \%, P=0.34 ; B$ vs worker number: $b \pm \mathrm{SD}=0.00 \pm 0.00, F_{1,15}=0.08, r^{2}=0 \%, P=0.79 ; B$ vs

Table 2 Number of new queens and new workers attributable to individual queens in four polygynous L. acervorum colonies

\begin{tabular}{|c|c|c|c|c|c|c|c|c|c|c|c|c|}
\hline Colony & & A & B & $\mathrm{C}$ & $\mathrm{D}$ & $\mathrm{E}$ & $\mathrm{F}$ & G & $\mathrm{H}$ & $\mathrm{U}$ & Totals & $P$ value \\
\hline \multirow[t]{2}{*}{ SD99.53 } & New queens & 0 & 2 & 7 & 2 & - & - & - & - & 4 & 15 & \multirow[t]{2}{*}{0.630} \\
\hline & New workers & 0 & 1 & 4 & 3 & - & - & - & - & 7 & 15 & \\
\hline \multirow[t]{2}{*}{ SD99.54 } & New queens & 0 & 2 & 0 & 10 & - & - & - & - & 9 & 21 & \multirow[t]{2}{*}{0.247} \\
\hline & New workers & 1 & 3 & 0 & 4 & - & - & - & - & 11 & 19 & \\
\hline \multirow[t]{2}{*}{ SD99.55 } & New queens & 2 & 4 & 4 & - & - & - & - & - & 5 & 15 & \multirow[t]{2}{*}{0.681} \\
\hline & New workers & 3 & 5 & 5 & - & - & - & - & - & 2 & 15 & \\
\hline \multirow[t]{2}{*}{ SD99.94 } & New queens & 1 & 0 & 0 & 0 & 0 & 4 & 0 & 0 & 0 & 5 & \multirow[t]{2}{*}{0.196} \\
\hline & New workers & 1 & 2 & 2 & 3 & 1 & 2 & 0 & 1 & 3 & 15 & \\
\hline
\end{tabular}

Individual queens (differing across colonies) are labelled A, B, C, etc. The final column (U) in each sequence per colony includes progeny of unknown parentage (i.e., progeny that could not be attributed to any queen within the colony). The queens in SD99.54 also include one 'lost' queen whose presence was inferred from progeny genotypes (see 'Reproductive skew' under 'Methods'). $P$ value is from exact probability tests of the null hypothesis that, within colonies, individual queens do not differ in the ratio of new workers and new queens produced. 
Table 3 Number of males and new workers attributable to individual queens in five polygynous L. acervorum colonies

\begin{tabular}{|c|c|c|c|c|c|c|c|c|c|}
\hline Colony & & A & $\mathrm{B}$ & $\mathrm{C}$ & $\mathrm{D}$ & $\mathrm{E}$ & $\mathrm{U}$ & Totals & $P$ value \\
\hline \multirow[t]{2}{*}{ SD99.55 } & Males & 0 & 9 & 0 & - & - & 6 & 15 & \multirow[t]{2}{*}{0.008} \\
\hline & New workers & 3 & 5 & 5 & - & - & 2 & 15 & \\
\hline \multirow[t]{2}{*}{ SD99.61 } & Males & 0 & 7 & - & - & - & 9 & 16 & \multirow[t]{2}{*}{0.005} \\
\hline & New workers & 0 & 14 & - & - & - & 1 & 15 & \\
\hline \multirow[t]{2}{*}{ SD99.64 } & Males & 10 & 0 & 2 & - & - & 2 & 14 & \multirow[t]{2}{*}{$<0.0001$} \\
\hline & New workers & 0 & 7 & 8 & - & - & 8 & 23 & \\
\hline \multirow[t]{2}{*}{ SD99.74 } & Males & 0 & 0 & 0 & 1 & 6 & 0 & 7 & \multirow[t]{2}{*}{$<0.0001$} \\
\hline & New workers & 1 & 1 & 1 & 4 & 0 & 8 & 15 & \\
\hline \multirow[t]{2}{*}{ SD99.78 } & Males & 0 & 0 & 17 & - & - & 0 & 17 & \multirow[t]{2}{*}{$<0.0001$} \\
\hline & New workers & 2 & 8 & 4 & - & - & 1 & 15 & \\
\hline
\end{tabular}

Individual queens (differing across colonies) are labelled A, B, C, etc. The final column (U) in each sequence per colony includes progeny of unknown parentage (i.e., progeny that could not be attributed to any queen within the colony). The queens in SD99.64 and SD99.74 also each include one 'lost' queen whose presence was inferred from progeny genotypes (see 'Reproductive skew' under 'Methods'). $P$ value is from exact probability tests of the null hypothesis that, within colonies, individual queens do not differ in the ratio of males and new workers produced. All $P$ values are also significant after sequential Bonferroni correction.

worker number per queen: $b \pm \mathrm{SD}=0.00 \pm 0.00, F_{1,15}=0.21$, $r^{2}=0 \%, P=0.65 ; B_{\text {adj }}$ vs relatedness: $b \pm \mathrm{SD}=-0.03 \pm 0.09$, $F_{1,15}=0.12, r^{2}=1 \%, P=0.74 ; B_{\text {adj }}$ vs queen number: $b \pm \mathrm{SD}=0.00 \pm 0.02, \quad F_{1,15}=0.68, r^{2}=1 \%, P=0.80 ; B_{\text {adj }}$ vs worker number: $b \pm \mathrm{SD}=0.00 \pm 0.00, F_{1,15}=0.01, r^{2}=0 \%$, $P=0.95 ; B_{\text {adj }}$ vs worker number per queen: $b \pm \mathrm{SD}=$ $\left.0.00 \pm 0.00, F_{1,15}=0.09, r^{2}=1 \%, P=0.77\right)$. We also found that

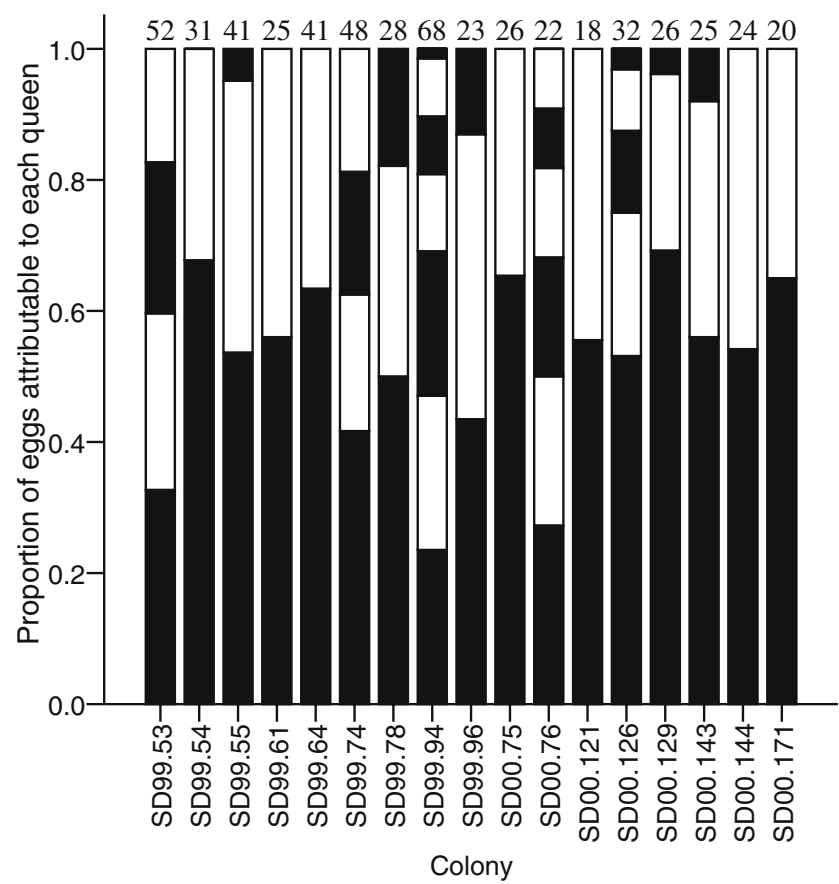

Fig. 1 Relative proportions of female eggs produced by queens within 17 polygynous Leptothorax acervorum colonies. Alternating black and white segments of each bar represent the proportion of female eggs attributable to different queens within a given colony. Numbers above bars equal the number of female eggs per colony that were successfully attributed to resident queens (total $n=550$ ) relatedness did not vary significantly with worker number (productivity GLM: $F_{1,15}=0.04, P=0.84$ ) or queen number (queen number GLM: $F_{1,15}=0.01, P=0.91$ ).

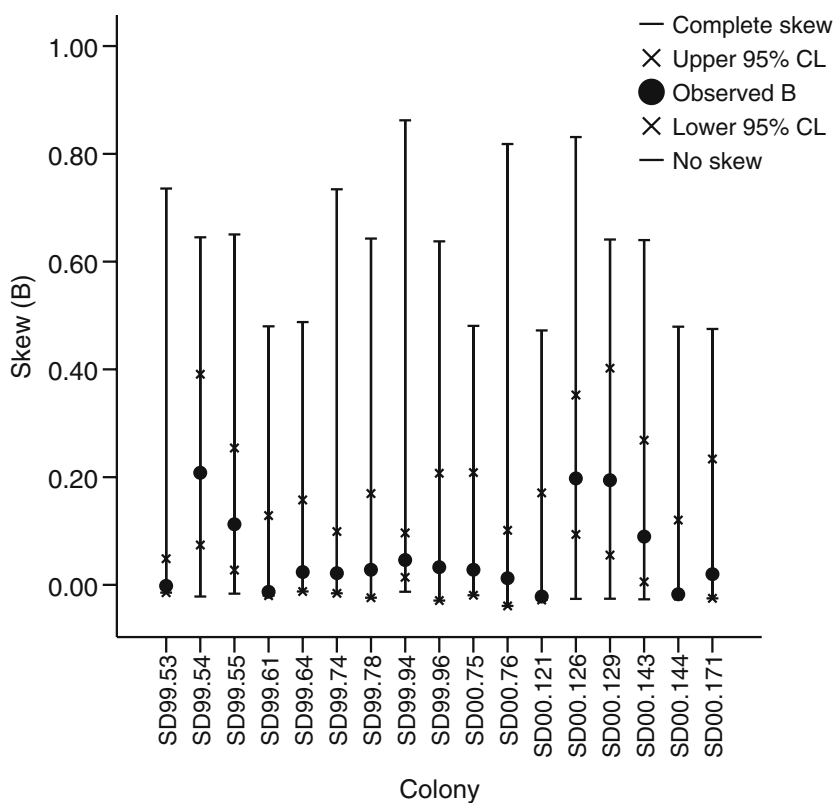

Fig. 2 Reproductive skew, as estimated by the $B$ index among female eggs, in 17 polygynous $L$. acervorum colonies. For each colony, upper horizontal bar ('-') denotes the maximum value of $B$ (i.e., value if one queen monopolizes all reproduction), given the observed number of queens in the colony; upper ' $X$ ' denotes the upper $95 \%$ confidence limit of $B$, based on 10,000 randomizations; filled circle denotes observed $B$; lower ' $\times$ ' denotes lower $95 \%$ confidence limit of $B$, based on 10,000 randomizations; lower horizontal bar ('-') denotes the minimum value of $B$ (i.e., value if all queens share reproduction equally), given the observed number of queens in the colony. Following Bonferroni correction, skew was significantly greater than expected by chance in five colonies (SD99.54, SD99.55, SD99.94, SD00.126 and SD00.129) and marginally greater than expected by chance in a sixth colony (SD00.143) 

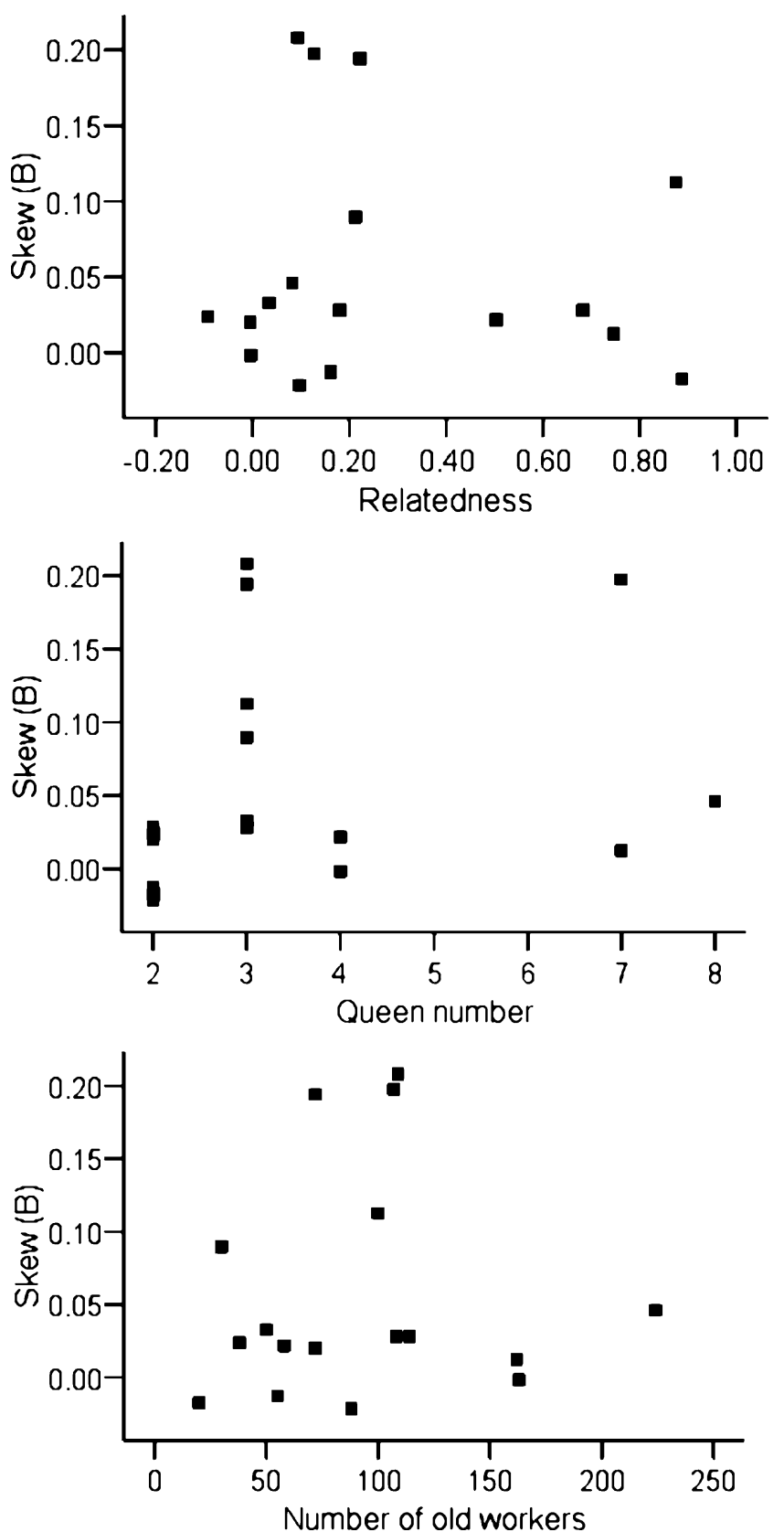

Fig. 3 Variation in reproductive skew, as estimated by the $B$ index among female eggs, in 17 polygynous $L$. acervorum colonies as a function of queen-queen relatedness within colonies (upper figure), queen number (middle figure) and number of old (adult) workers (representing a measure of productivity; lower figure)

\section{Discussion}

Using parentage analyses based on microsatellite markers, we measured skew among female eggs in a sample of 17 polygynous colonies taken from a field population of the ant $L$. acervorum. Skew tended to be low, consistent with previous data showing that nearly all queens participate in egg laying (Bourke 1991) and that the maternity of new queens is shared (Bourke et al. 1997). However, despite wide variation in queen-queen relatedness, we found no significant association of skew with relatedness. We also found no significant association of skew with productivity (as measured by worker number) or per capita productivity. These findings were contrary to the predictions of the concession model of reproductive skew (Table 1). Furthermore, contrary to the prediction of the tug-of-war model (Table 1), we found no significant association of relatedness and productivity (as measured by worker number). The absence of a significant association between relatedness and queen number was consistent with our previous findings from an overlapping data set (Hammond et al. 2001). Overall, our results failed to match any single current skew model predicting an association of skew with the variables that we investigated (Table 1). In this, our results are consistent with the majority of similar, within-population studies of the expected correlates of skew in other social Hymenoptera, especially ants (see 'Introduction').

Our principal measure of reproductive skew was the degree to which coexisting queens shared the parentage of female (diploid) eggs. We selected this measure because of the high turnover among L. acervorum queens in the study population (Bourke et al. 1997; present study), which meant that offspring sampled as adults would no longer have been assignable to resident queens. This measure of skew assumed that egg-to-adult survival of female eggs does not vary with parentage, that queens do not differ in the chances of their female eggs developing into adult queens or workers and that skew among female progeny matches skew among male progeny. The first of these assumptions is plausible because, although differential mortality stemming from nepotism has been found in the polygynous ant Formica fusca (Hannonen and Sundström 2003b), L. acervorum queens, although known to eat eggs, do not discriminate eggs by their maternal origin (Bourke 1994). Likewise, as regards the second assumption, although coexisting queens have been shown to differ in their relative contributions to worker and queen progeny in some polygynous ant species (Ross 1988; Pamilo and Seppä 1994), in the present study, we found that $L$. acervorum queens contributed similar shares to worker and queen progeny (see also Rüppell et al. 2002). This finding is consistent with queen-worker caste fate being environmentally determined in Leptothorax (Wesson 1940). It also suggests that the workers' biasing of caste fate that we have previously described in L. acervorum (Hammond et al. 2002) is exercised randomly with respect to female parentage. Contrary to our third assumption, we found that coexisting $L$. acervorum queens exhibited significant variation in their relative contributions to female and male progeny (cf. Fournier and Keller 2001). In general, skew among male progeny was higher than among female progeny $(B=0.56$ and 0.15 among males and new workers, 
respectively, and $B_{\text {adj }}=0.67$ and 0.28 among males and new workers, respectively; data from five colonies in Table 3), from which it follows that skew among sexual progeny as a whole would be higher than skew estimated among females only. However, this does not necessarily affect our main conclusions regarding the lack of association between skew and its predicted correlates across colonies. This is because it seems unlikely that skew in males would vary as a function of variables with which we found skew among females to be uncorrelated.

Previous evidence suggests that leptothoracine ants exhibit a positive relationship of skew with relatedness at the between-population and between-species level, as the concession model of skew evolution predicts (see 'Introduction'). However, within-population studies reveal either no relationship (present study) or a negative relationship (Rüppell et al. 2002). Applied within populations, skew models assume that coexisting breeders are capable of assessing within-group relatedness and adjusting their share of reproduction accordingly. At first sight, two pieces of evidence suggest that $L$. acervorum queens in polygynous colonies could be capable of assessing queenqueen relatedness. The first is the negative relationship of skew and relatedness in L. rugatulus (Rüppell et al. 2002). The second is the existence of worker-controlled sex ratios associated with variation in relative colony-level relatedness asymmetry (relative relatedness to the sexes) in L. acervorum and other ant species (Chan and Bourke 1994; Sundström 1994; Evans 1995; Sundström et al. 1996), a precondition for which is workers' assessment of relatedness asymmetry. However, in L. rugatulus (but not L. acervorum), queens are dimorphic, with small-bodied queens (microgynes) producing relatively more sexuals than large-bodied queens (macrogynes) (Rüppell et al. 2002). Furthermore, microgynes tend to be less related than macrogynes (Rüppell et al. 2001). Therefore, unlike L. acervorum queens, L. rugatulus queens may have a physical cue (frequency of nestmate microgynes) that covaries with relatedness and, at least partly, predicts nestmates' share of reproduction. As regards workers' assessment of relatedness asymmetry, it is likely that such assessment, which occurs on the basis of chemical cues (Boomsma et al. 2003), is an easier chemosensory task than queens' assessment of queen-queen relatedness since it almost certainly requires discriminations on a coarser scale. Therefore, it remains possible that $L$. acervorum queens in polygynous colonies are unable to assess within-colony relatedness and that this is why they fail to adjust their levels of skew as a function of relatedness varying within populations.

In addition to processes in the concession models operating at the population level, other factors may contribute to the maintenance of low skew in the study population of $L$. acervorum (and other polygynous ants sharing its biology). One is indiscriminate infanticide in the form of indiscriminate egg cannibalism (Bourke 1991, 1994). Coupled with low costs of offspring (egg) production, this is predicted to promote low skew by a model of Johnstone and Cant (1999a). Another is split sex ratios (Chan and Bourke 1994; Chan et al. 1999; Hammond et al. 2002). These could interact with skew evolution to reward the maintenance of low skew in polygynous colonies, given that queens achieving reproductive monopoly within polygynous colonies should lose fitness through their workers rearing less-valuable daughters from the sexual brood (Bourke 2001; Nonacs 2002). Future work in $L$. acervorum and other species should therefore concentrate on (a) further testing of which assumptions of the differing skew models are applicable, (b) greater integration of the differing skew models into a single comprehensive framework (e.g., Johnstone 2000) and (c) the experimental testing of the models' predictions (e.g., Langer et al. 2004).

Acknowledgements We thank Peter Nonacs, Seirian Sumner and an anonymous referee for helpful comments and advice. The Forestry Commission kindly granted permission to collect samples. This work was supported by a grant (GR3/11792) from the UK Natural Environment Research Council to AFGB and MWB. Rob Hammond was supported by Swiss National Science Foundation grants awarded to Laurent Keller while this paper was written. The work in this paper complies with current UK law.

\section{References}

Boomsma JJ, Nielsen J, Sundström L, Oldham NJ, Tentschert J, Petersen HC, Morgan ED (2003) Informational constraints on optimal sex allocation in ants. Proc Natl Acad Sci USA 100:8799-8804

Bourke AFG (1991) Queen behaviour, reproduction and egg cannibalism in multiple-queen colonies of the ant Leptothorax acervorum. Anim Behav 42:295-310

Bourke AFG (1994) Indiscriminate egg cannibalism and reproductive skew in a multiple-queen ant. Proc R Soc Lond B 255:55-59

Bourke AFG (2001) Reproductive skew and split sex ratios in social Hymenoptera. Evolution 55:2131-2136

Bourke AFG, Heinze J (1994) The ecology of communal breeding: the case of multiple-queen leptothoracine ants. Philos Trans R Soc Lond B 345:359-372

Bourke AFG, Green HAA, Bruford MW (1997) Parentage, reproductive skew and queen turnover in a multiple-queen ant analysed with microsatellites. Proc R Soc Lond B 264:277-283

Buschinger A (1973) The role of daily temperature rhythms in brood development of ants of the tribe Leptothoracini (Hymenoptera; Formicidae). In: Wieser W (ed) Effects of temperature on ectothermic organisms. Springer, Berlin Heidelberg New York, pp 229-232

Buschinger A (1974) Monogynie und Polygynie in Insektensozietäten. In: Schmidt GH (ed) Sozialpolymorphismus bei Insekten. Wissenschaftliche Verlagsgesellschaft, Stuttgart, pp 862-896

Cant MA (1998) A model for the evolution of reproductive skew without reproductive suppression. Anim Behav 55:163-169

Cant MA (2006) A tale of two theories: parent-offspring conflict and reproductive skew. Anim Behav 71:255-263 
Cant MA, Johnstone RA (1999) Costly young and reproductive skew in animal societies. Behav Ecol 10:178-184

Cant MA, Johnstone RA (2000) Power struggles, dominance testing, and reproductive skew. Am Nat 155:406-417

Chan GL, Bourke AFG (1994) Split sex ratios in a multiple-queen ant population. Proc R Soc Lond B 258:261-266

Chan GL, Hingle A, Bourke AFG (1999) Sex allocation in a facultatively polygynous ant: between-population and betweencolony variation. Behav Ecol 10:409-421

Clutton-Brock TH (1998) Reproductive skew, concessions and limited control. Trends Ecol Evol 13:288-292

Douwes P, Sivusaari L, Niklasson M, Stille B (1987) Relatedness among queens in polygynous nests of the ant Leptothorax acervorum. Genetica 75:23-29

Emlen ST (1982a) The evolution of helping. I. An ecological constraints model. Am Nat 119:29-39

Emlen ST (1982b) The evolution of helping. II. The role of behavioral conflict. Am Nat 119:40-53

Emlen ST (1997) Predicting family dynamics in social vertebrates. In: Krebs JR, Davies NB (eds) Behavioural ecology: an evolutionary approach. Blackwell, Oxford, pp 228-253

Evans JD (1993) Parentage analyses in ant colonies using simple sequence repeat loci. Mol Ecol 2:393-397

Evans JD (1995) Relatedness threshold for the production of female sexuals in colonies of a polygynous ant, Myrmica tahoensis, as revealed by microsatellite DNA analysis. Proc Natl Acad Sci USA 92:6514-6517

Fanelli D, Boomsma JJ, Turillazzi S (2005) Multiple reproductive strategies in a tropical hover wasp. Behav Ecol Sociobiol 58:190-199

Felke M, Buschinger A (1999) Social organization, reproductive behavior and ecology of Leptothorax acervorum (Hymenoptera, Formicidae) from the Sierra de Albarracin in central Spain. Insectes Soc 46:84-91

Field J, Solís CR, Queller DC, Strassmann JE (1998) Social and genetic structure of paper wasp cofoundress associations: tests of reproductive skew models. Am Nat 151:545-563

Foitzik S, Haberl M, Gadau J, Heinze J (1997) Mating frequency of Leptothorax nylanderi ant queens determined by microsatellite analysis. Insectes Soc 44:219-227

Fournier D, Keller L (2001) Partitioning of reproduction among queens in the Argentine ant, Linepithema humile. Anim Behav 62:1039-1045

Fournier D, Aron S, Keller L (2004) Significant reproductive skew in the facultatively polygynous ant Pheidole pallidula. Mol Ecol 13:203-210

Hamaguchi K, Itô Y, Takenaka O (1993) GT dinucleotide repeat polymorphisms in a polygynous ant, Leptothorax spinosior and their use for measurement of relatedness. Naturwissenschaften 80:179-181

Hamilton WD (1964) The genetical evolution of social behaviour I, II. J Theor Biol 7:1-52

Hammond RL, Bourke AFG, Bruford MW (2001) Mating frequency and mating system of the polygynous ant, Leptothorax acervorum. Mol Ecol 10:2719-2728

Hammond RL, Bruford MW, Bourke AFG (2002) Ant workers selfishly bias sex ratios by manipulating female development. Proc R Soc Lond B 269:173-178

Hammond RL, Bruford MW, Bourke AFG (2003) Male parentage does not vary with colony kin structure in a multiple-queen ant. J Evol Biol 16:446-455

Hannonen M, Sundström L (2003a) Reproductive sharing among queens in the ant Formica fusca. Behav Ecol 14:870-875

Hannonen M, Sundström L (2003b) Worker nepotism among polygynous ants. Nature 421:910

Heinze J (1995) Reproductive skew and genetic relatedness in Leptothorax ants. Proc R Soc Lond B 261:375-379
Heinze J, Lipski N (1990) Fighting and usurpation in colonies of the palaearctic ant Leptothorax gredleri. Naturwissenschaften 77:493-495

Heinze J, Oberstadt B (2003) Costs and benefits of subordinate queens in colonies of the ant, Leptothorax gredleri. Naturwissenschaften 90:513-516

Heinze J, Smith TA (1990) Dominance and fertility in a functionally monogynous ant. Behav Ecol Sociobiol 27:1-10

Heinze J, Lipski N, Hölldobler B, Bourke AFG (1995a) Geographical variation in the social and genetic structure of the ant, Leptothorax acervorum. Zoology 98:127-135

Heinze J, Lipski N, Schlehmeyer K, Hölldobler B (1995b) Colony structure and reproduction in the ant, Leptothorax acervorum. Behav Ecol 6:359-367

Johnstone RA (2000) Models of reproductive skew: a review and synthesis. Ethology 106:5-26

Johnstone RA, Cant MA (1999a) Reproductive skew and indiscriminate infanticide. Anim Behav 57:243-249

Johnstone RA, Cant MA (1999b) Reproductive skew and the threat of eviction: a new perspective. Proc R Soc Lond B 266:275-279

Johnstone RA, Woodroffe R, Cant MA, Wright J (1999) Reproductive skew in multimember groups. Am Nat 153:315-331

Keller L, Reeve HK (1994) Partitioning of reproduction in animal societies. Trends Ecol Evol 9:98-102

Kokko H (2003) Are reproductive skew models evolutionarily stable? Proc R Soc Lond B 270:265-270

Kokko H, Johnstone RA (1999) Social queuing in animal societies: a dynamic model of reproductive skew. Proc R Soc Lond B 266:571-578

Langer P, Hogendoorn K, Keller L (2004) Tug-of-war over reproduction in a social bee. Nature 428:844-847

Langer P, Hogendoorn K, Schwarz MP, Keller L (2006) Reproductive skew in the Australian allodapine bee Exoneura robusta. Anim Behav 71:193-201

Liebert AE, Starks PT (2006) Taming of the skew: transactional models fail to predict reproductive partitioning in the paper wasp Polistes dominulus. Anim Behav 71:913-923

Magrath RD, Heinsohn RG (2000) Reproductive skew in birds: models, problems and prospects. J Avian Biol 31:247-258

Nonacs P (2000) Measuring and using skew in the study of social behavior and evolution. Am Nat 156:577-589

Nonacs P (2002) Sex ratios and skew models: the special case of evolution of cooperation in polistine wasps. Am Nat 160:103-118

Nonacs P (2003) Measuring the reliability of skew indices: is there one best index? Anim Behav 65:615-627

Nonacs P, Reeve HK, Starks PT (2004) Optimal reproductive-skew models fail to predict aggression in wasps. Proc R Soc Lond B 271:811-817

Nonacs P, Liebert AE, Starks PT (2006) Transactional skew and assured fitness return models fail to predict patterns of cooperation in wasps. Am Nat 167:467-480

Pamilo P, Seppä P (1994) Reproductive competition and conflicts in colonies of the ant Formica sanguinea. Anim Behav 48: $1201-1206$

Pedersen JS, Boomsma JJ (1999) Effect of habitat saturation on the number and turnover of queens in the polygynous ant, Myrmica sulcinodis. J Evol Biol 12:903-917

Queller DC, Goodnight KF (1989) Estimating relatedness using genetic markers. Evolution 43:258-275

Ragsdale JE (1999) Reproductive skew theory extended: the effect of resource inheritance on social organization. Evol Ecol Res $1: 859-874$

Reeve HK (1991) Polistes. In: Ross KG, Matthews RW (eds) The social biology of wasps. Comstock Publishing Associates, Ithaca, pp 99-148 
Reeve HK (2000) A transactional theory of within-group conflict. Am Nat 155:365-382

Reeve HK, Emlen ST (2000) Reproductive skew and group size: an N-person staying incentive model. Behav Ecol 11:640-647

Reeve HK, Keller L (2001) Tests of reproductive-skew models in social insects. Annu Rev Entomol 46:347-385

Reeve HK, Ratnieks FLW (1993) Queen-queen conflicts in polygynous societies: mutual tolerance and reproductive skew. In: Keller L (ed) Queen number and sociality in insects. Oxford University Press, Oxford, pp 45-85

Reeve HK, Emlen ST, Keller L (1998) Reproductive sharing in animal societies: reproductive incentives or incomplete control by dominant breeders? Behav Ecol 9:267-278

Reeve HK, Starks PT, Peters JM, Nonacs P (2000) Genetic support for the evolutionary theory of reproductive transactions in social wasps. Proc R Soc Lond B 267:75-79

Rice WR (1989) Analyzing tables of statistical tests. Evolution 43:223-225

Ross KG (1988) Differential reproduction in multiple-queen colonies of the fire ant Solenopsis invicta (Hymenoptera: Formicidae). Behav Ecol Sociobiol 23:341-355

Rüppell O, Heinze J, Hölldobler B (2001) Alternative reproductive tactics in the queen-size-dimorphic ant Leptothorax rugatulus (Emery) and their consequences for genetic population structure. Behav Ecol Sociobiol 50:189-197
Rüppell O, Heinze J, Hölldobler B (2002) Intracolonial patterns of reproduction in the queen-size dimorphic ant Leptothorax rugatulus. Behav Ecol 13:239-247

Seppä P, Queller DC, Strassmann JE (2002) Reproduction in foundress associations of the social wasp, Polistes carolina: conventions, competition, and skew. Behav Ecol 13:531-542

Sumner S, Casiraghi M, Foster W, Field J (2002) High reproductive skew in tropical hover wasps. Proc R Soc Lond B 269: 179-186

Sundström L (1994) Sex ratio bias, relatedness asymmetry and queen mating frequency in ants. Nature 367:266-268

Sundström L, Chapuisat M, Keller L (1996) Conditional manipulation of sex ratios by ant workers: a test of kin selection theory. Science 274:993-995

Vehrencamp SL (1979) The roles of individual, kin, and group selection in the evolution of sociality. In: Marler P, Vandenbergh JG (eds) Handbook of behavioral neurobiology. vol. 3. Social behavior and communication. Plenum, New York, pp 351-394

Vehrencamp SL (1983) Optimal degree of skew in cooperative societies. Am Zool 23:327-335

Wesson LG (1940) An experimental study on caste determination in ants. Psyche 47:105-111

Zink AG, Reeve HK (2005) Predicting the temporal dynamics of reproductive skew and group membership in communal breeders. Behav Ecol 16:880-888 